\title{
Impact assessment of bioclogging on hydraulic conductivity of porous media
}

\author{
Kushal Singh ${ }^{1}$, S, Visali ${ }^{1}$, A. Kumar ${ }^{1}$, L. Sushma ${ }^{1}$, and P. Devi ${ }^{1}$ \\ ${ }^{1}$ National Geophysical Research Institute CSIR
}

July 7,2020

\begin{abstract}
Microorganisms can do physical and chemical transformations in the media during their growth in an organic-rich favorable environment. Adequate infiltration of organic-rich water into the porous media such as aquifers may cause intensive microbial activity and clog the pores by microorganisms. A sandbox laboratory experiment has been conducted for understanding impact assessment of bioclogging on the hydraulic properties of the porous media caused by aerobic and anaerobic microbial activities. A tank packed with medium-grained sand was saturated with growth medium prepared by dissolving source of organic matter, nitrate, sulfate, and iron in a tap water. To grow the complex microbial species in the tank, a $10 \mathrm{ml}$ bacterial seed taken from the Winogradsky column was injected in the middle of the tank at a depth of $10 \mathrm{~cm}$. To achieve the preset objective, bacterial population density and hydraulic measurements both in aerobic and anaerobic zones were conducted every 15 days and 30 days, respectively. This study reveals that hydraulic conductivity is initially increased in the aerobic zone and subsequently begins decreasing, whereas, in the anaerobic region, it reduces during the entire period of experimentation. It is also found that the conductivity in the anaerobic zone decreases with an increase in bacterial populations of nitrate, iron, and sulfate reducers. However, in the aerobic zone, hydraulic conductivity increases with an increase in population E.coli due to the dissolution of sand grains induced by aerobic and facultative microorganisms.
\end{abstract}

\section{Hosted file}

manuscript_HP-KPS.docx available at https ://authorea.com/users/340565/articles/467752-impactassessment-of-bioclogging-on-hydraulic-conductivity-of-porous-media 


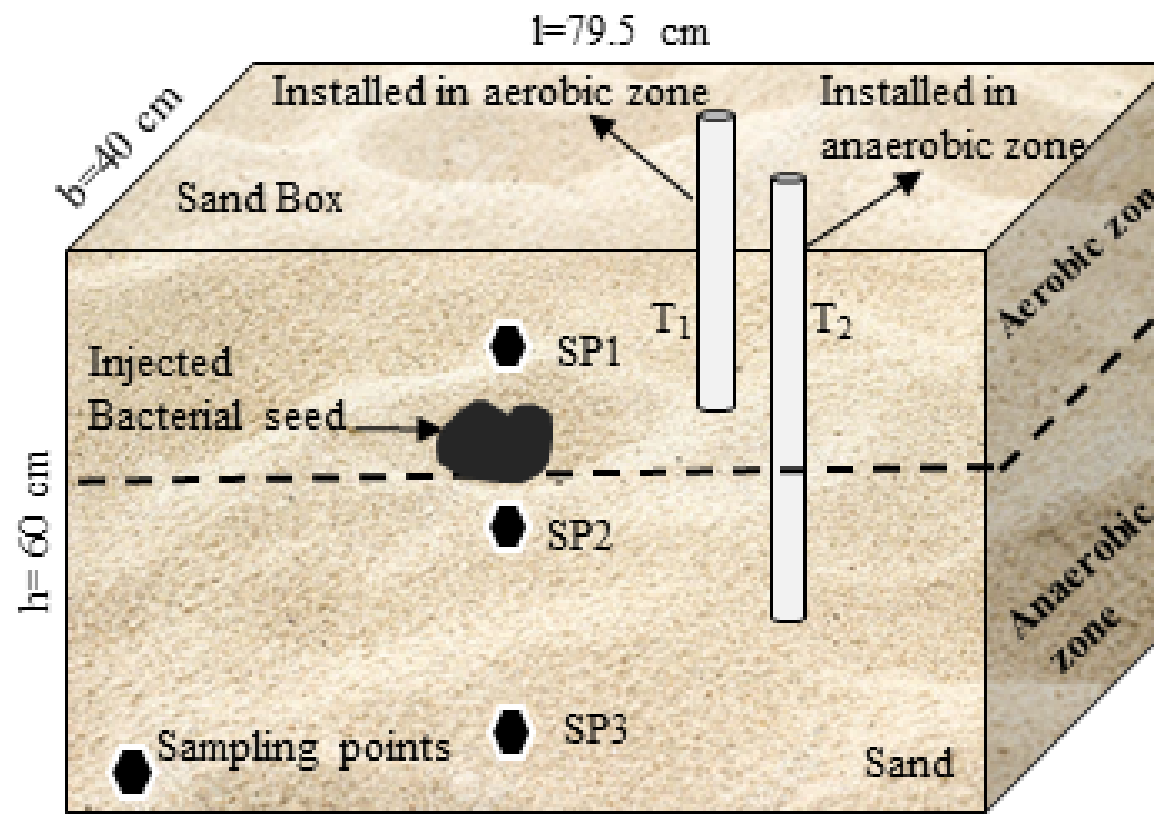



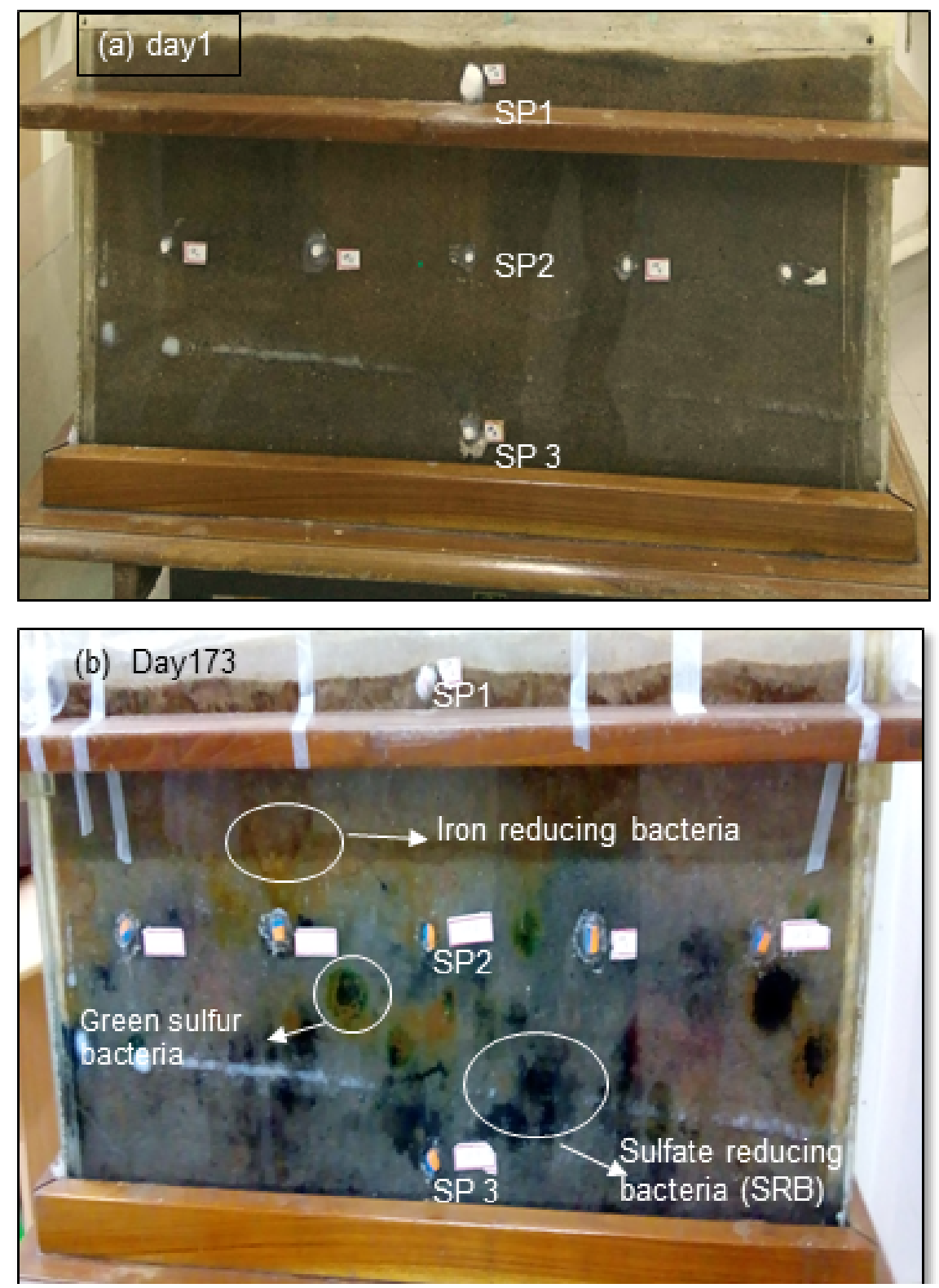

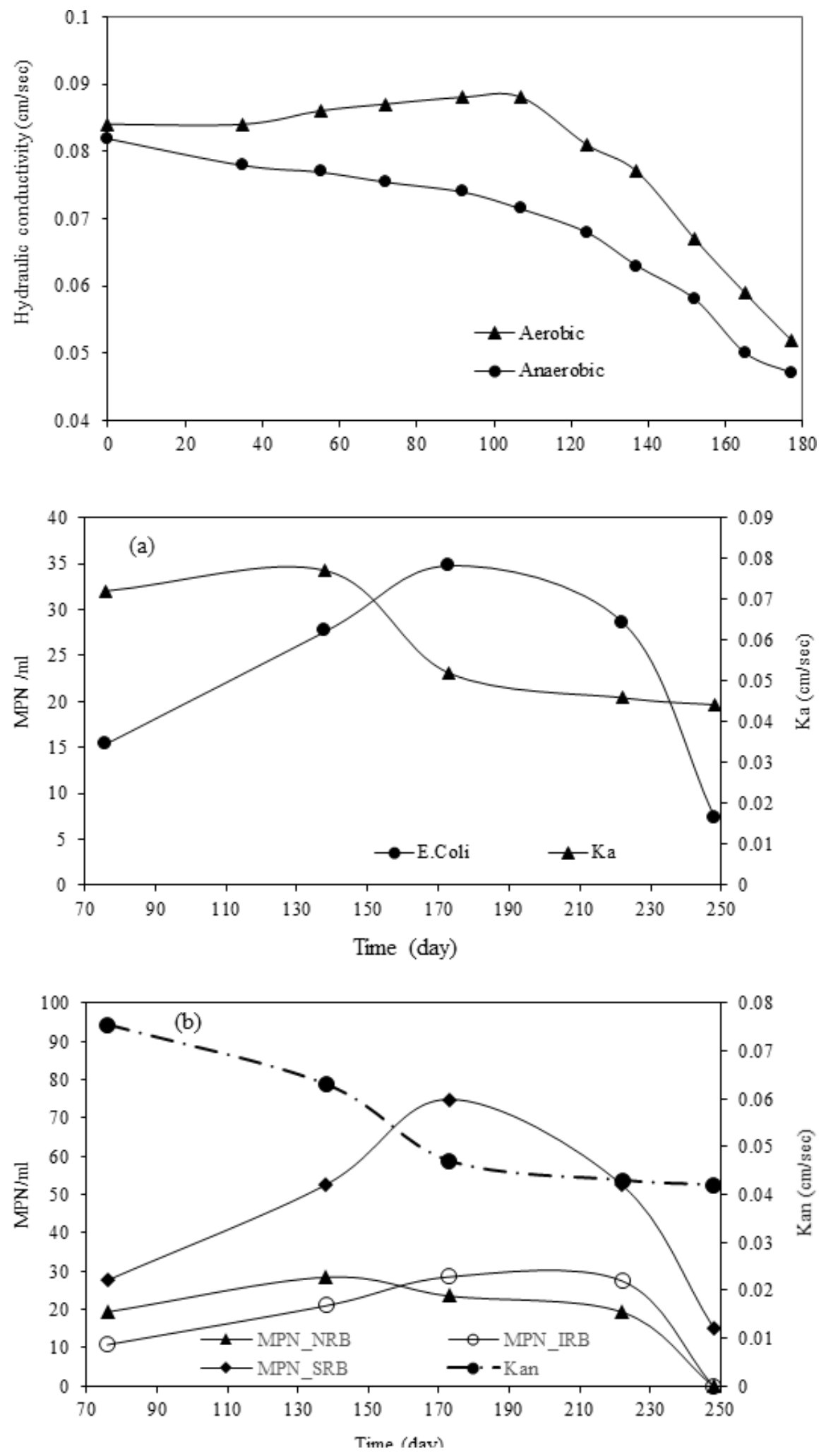

Hosted file 
Table_1.docx available at https://authorea.com/users/340565/articles/467752-impactassessment-of-bioclogging-on-hydraulic-conductivity-of-porous-media 